\section{TÀI LIÊU THAM KHẢO}

1. Macrae FA, Lamont JT, Grover S. Overview of colon polyps. UpToDate. Feb 2021.

2. Ngoan Tran Le, Hang Viet Dao. Colorectal Cancer in Viet Nam. October 19th 2020. DOI: 10.5772/intechopen.93730. October 1

3. Wickramasinghe DP, Samaranayaka SF, Lakmal C, Mathotaarachchi S, et al. Types and Patterns of Colonic Polyps Encountered at a Tertiary Care Center in a Developing Country in South Asia. Hindawi Publishing Corporation Analytical Cellular Pathology.Volume 2014, Article ID 248142,4 pages

4. Jayadevan $\mathbf{R}$, Anithadevi $\mathbf{T} \mathbf{S}$. Prevalence of colorectal polyps: a retrospective study to determine of the Cut-Off Age for Screening. Journal of Gastroenterology, Pancreatology \& Liver Disorders.2016.DO - 10.15226/2374-815X/3/2/00156.
5. Thái Thị Hông Nhung, Trịnh Đăng Khoa. Nghiên cứu đặc điểm lâm sàng, hình ảnh nội soi, mô bênh hoc và đánh giá kết quả cắt đốt polyp ĐTT qua nội soi tại Bệnh viện Trường Đai học Y Dược Cần Thơ. TC Y Dược học Cần Thơ. Số 22-2324-25/2019.

6. Piérola LBF, Fernández JC, Aguinaga FM, Muruamendiaraz LH, Malaver CJC (2013). "Malignant Colorectal Polyps: Diagnosis, Treatment and Prognosis". Colonoscopy and Colorectal Cancer Screening: Future Directions. doi:10.5772/52697

7. Lee YM, Huh KC. Clinical and Biological Features of Interval Colorectal Cancer. Clin Endosc 2017;50:254-260.

8. Baran B, Ozupek NM, Tetik NY, Acar E, et al. Difference Between Left-Sided and Right-Sided Colorectal Cancer: A Focused Review of Literature, Gastroenterol Res. 2018;11(4):264-273.

\title{
SO SÁNH HIỆU QUẢ GIẢM ĐAU SAU PHẪU THUẬT THOÁT VỊ BẸN Ở TRẺ EM BẰNG GÂY TÊ THẦN KINH CHẤU BẸN CHẤU HẠ VI VỚI GÂY TÊ KHOANG CÙNG
}

\section{TÓM TẮT}

Nghiên cứu thử nghiệm lâm sàng ngẫu nhiên có đối chứng trên 60 bênh nhi được phâuu thuâtt thoát vị bẹn. Các bệnh nhân được gây mê Mask thanh quản thường quy, sau đó chia làm 2 nhóm: Nhóm I gây tê khoang cùng dựa theo mốc giải phẫu bằng Levobupivacain $0.2 \%, 0.8 \mathrm{ml} / \mathrm{kg}$. Nhóm II gây tê chậu bẹn chậu hạ vị dưới hướng dẫn của siêu âm bằng Levobupivacain $0.2 \%, 0,3 \mathrm{ml} / \mathrm{kg}$. Chất lương tê theo Gunter ở mức tốt là $90 \%$ đối với nhóm I và $86,7 \%$ đối với nhóm II; thời gian giảm đau sau mổ ở nhóm I là 324 phút, nhóm II là 312 phút, sự khác biệt giữa 2 nhóm không có ý nghĩa thống kê với $p>0,05$. Ngay sau khi tỉnh, $100 \%$ bệnh nhân nhóm II vận động được ở mức $M_{0}$. 30 phút sau khi tỉnh 2 bn ở nhóm I (6.7\%) chưa hồi phục vận động hoàn toàn. Các tác dụng không mong muổn của 2 nhóm đều thấp và khổng nguy hiểm. Kết luận: nhóm gây tê chậu bẹn chậu hạ vị dưới hướng dẫn của siêu âm có hiệu quả giảm đau sau mổ tốt tương đương với nhóm gây tể khoang cùng, thời gian phục hồi vận động ngắn hơn và lượng thuốc tê sử dung ít hơn.

Tư khóa: Gây tê khoang cùng, gây tê chậu bẹn chậu hạ vị

${ }^{1}$ Bộ môn GMHS, Trường đại học Y Hà Nội

${ }^{2}$ Bệnh viện Đa khoa tỉnh Hưng Yên

${ }^{3}$ Bềnh viện Viết Đức

Chịu trách nhiệm chính: Phạm Quang Minh

Email: quangminhvietduc@yahoo.com

Ngày nhận bài: 10.9 .2021

Ngày phản biên khoa hoc: 12.11.2021

Ngày duyệt bài: 18.11.2021
Phạm Quang Minh ${ }^{1}$, Hoàng Thị Hà ${ }^{2}$, Lưu Quang Thùy ${ }^{3}$, Vũ Hoàng Phương ${ }^{1}$

\section{SUMMARY}

TO COMPARE THE EFFECT OF PAIN RELIEF POSTOPERATION IN PEDIATRIC INGUINAL HERNIA SURGERY BETWEEN \section{ILIOINGUINAL/ILIOHYPOGASTRIC} NERVES BLOCK TO CAUDAL BLOCK

A randomized controlled clinical trial of 60 pediatric patients undergoing inguinal hernia surgery. The patients were given routine laryngeal mask anesthesia, then were divided into 2 groups: Group I: the patients were given analgesia by caudal block based on anatomical landmarks with levobupivacaine $0.2 \%, 0.8 \mathrm{ml} / \mathrm{kg}$. Group II: the patients was given analgesia by ilioinguinal/iliohypogastric nerves block under ultrasound guidance with levobupivacaine $0.2 \%, 0.3 \mathrm{ml} / \mathrm{kg}$. Quality of numbness according to Gunter score: attending at a good level were $90 \%$ for group I and $86.7 \%$ for group II; pain relief time after surgery in group I was 324 minutes, group II was 312 minutes, the difference between the two groups was not statistically significant with $p>0.05$. Immediately after awakening, $100 \%$ of patients in group II were able to move their legs at the level of M0. 30 minutes after awakening, 2 patients in group I $(6.7 \%)$ had not fully recovered. The side effects of the 2 groups were low and not dangerous. Conclusion: The ilioinguinal/iliohypogastric nerve blocks group had good postoperative analgesia similar to that of the caudal block group, the recovery time was shorter, and the amount of anesthetic drug used was lower.

Keyword: Caudal block, ilioinguinal/iliohypogastric nerve blocks 


\section{I. ĐĂT VẤN ĐỀ}

Phẫu thuật vùng tiểu khung chiếm $40 \%$ tổng số phẫu thuật ở trẻ em, phổ biến như phẫu thuật thoát vị bẹn, nang thừng tinh, ẩn tinh hoàn. Trong đó gây tê khoang cùng là một biện pháp giảm đau trong và sau mổ thường được lựa chọn vì dễ thực hiện về mặt kỹ thuật, tỳ lệ thành công cao. Đâuu những năm 2000 tới nay, với sự phát triển của khoa học kỹ thuật, các phương tiện chẩn đoán hình ảnh được áp dụng rộng rãi, dưới sự hướng dẫn của siêu âm, phương pháp gây tê thân thần kinh ngoại biên ${ }^{1}$ được áp dụng rộng rãi để giảm đau vì hiệu quả cao và ít tổn thương thần kinh.

Kĩ thuật gây tê thần kinh chậu bẹn chậu hạ vị dưới hướng dẫn của siêu âm cũng không nằm ngoài xu hướng ây ${ }^{2.3}$ - một phương pháp giảm đau hiệu quả cho phẫu thuật vùng tiểu khung, đặc biệt là phẫu thuật thoát vị bẹn ở trẻ em ${ }^{4}$. Đây là loại phẫu thuật ngày càng phổ biến, các bệnh viện đang cố gắng rút ngắn thời gian trẻ nẳm viện, việc này đòi hỏi có biện pháp giảm đau sau mổ cho trẻ hiệu quả, an toàn. Kỹ thuật gây tê chậu bẹn chậu hạ vị mặc dù được chứng minh tính hiệu quả nhưng là một kỹ thuật khó và cần máy siêu âm, trong khi gây tê khoang cùng đã được tiến hành thường quy. Tại Việt Nam chưa có nghiên cứu nào về so sánh hai phương pháp gây tê này.

Vì vậy, chúng tôi thực hiện đề tài nhằm 2 mục tiêu: 1. So sánh hiệu quả giảm đau sau mô thoát vi bẹn ở trẻ em bằng phương pháp gây tê chậu bẹn chậu hạ vị với gây tê khoang cùng. 2 . Đánh giá một số tác dụng không mong muốn của 2 phương pháp giảm đau này

\section{II. ĐỐI TƯỢNG VÀ PHƯƠNG PHÁP NGHIÊN CỨU}

2.1. Đối tượng. Bệnh nhân có chỉ định phẫu thuật thoát vị bẹn một bên mổ mở theo kế hoach.

Tiêu chuẩn lựa chọn. Tuổi 1 - 8 tuổi; ASA I, II; BMI < 30; không có chống chỉ định gây tê. Gia đình bệnh nhi đồng ý thực hiện thủ thuật và hợp tác với thây thuốc.

Tiêu chuấn loại trừ. Bệnh nhân phải dùng Paracetamol để hạ sốt sau mổ. Bệnh nhân có tiền sử dị ứng với thuốc tê Levobupivacain

Tiêu chuẩn đưa ra khỏi nghiên cứu. Bố me hoặc người giám hộ không muốn bệnh nhân tiếp tục. Xuất hiện các biến chứng liên quan đến phấu thuật hoăc gây mê.

\subsection{Phương pháp nghiên cứu}

- Thiết kế: nghiên cứu tiến cứu, can thiệp lâm sàng ngẫu nhiên, có đối chứng.
- Địa điểm: Nghiên cứu tiến hành tại khoa GMHS, Bệnh viện nhi Trung ương.

Thời gian nghiên cứu: từ tháng 9/2020 đến tháng $7 / 2021$

- Cỡ mẫu: 60 bệnh nhân chia thành 02 nhóm theo phương pháp rút thăm ngẫu nhiên: Nhóm I: gây tê Caudal dựa theo mốc giải phẫu. Nhóm II: gây tê thần kinh chậu bẹn, chậu hạ vị dưới hướng dẫn của siêu âm.

\subsection{Phương pháp thực hiên}

- Khám và chuẩn bị bệnh nhẩn trước mổ theo quy trình của Bệnh viện Nhi TW

- Vào phòng mổ:

+ Trẻ được lắp theo dõi, làm đường truyền, truyền dịch tinh thể theo luật 4:2:1

+ Khởi mê bằng thuốc propofol $3,0 \mathrm{mg} / \mathrm{kg}$, fentanyl $1 \mathrm{mcg} / \mathrm{kg}$, đặt mask thanh quản, thơ máy $\mathrm{FiO}_{2} 40 \%-60 \%$, lưu lượng khí mới $2 \mathrm{l} /$ phút. Sau đó tiến hành gây tê vùng theo quy trình của Bệnh viện nhi trung ương:

- Nhóm I: Gây tê khoang cùng dựa theo mốc giải phẫu bằng Levobupivacain $0,2 \% \times 0,8 \mathrm{ml} / \mathrm{kg}^{5}$

- Nhóm II: Gây tê chậu bẹn chậu hạ vị dưới siêu âm bằng Levobupivacain $0,2 \% \times 0,3 \mathrm{ml} / \mathrm{kg}^{6}$

+ Duy trì mê bằng Servofluran 1 - 1,5 MAC. Theo dõi hiệu quả gây tê bằng thang điểm Gunter khi rạch da.

+ Thoát mê: ngừng Servofluran, rút mask thanh quản khi đủ điều kiện, chuyển bệnh nhi ra phòng hồi tỉnh.

Tất cả bệnh nhân của hai nhóm đều được dùng thuốc dự phòng nôn bằng ondasetron $0,1 \mathrm{mg} / \mathrm{kg}$ và dexamethasone $0,1 \mathrm{mg} / \mathrm{kg}$, giảm đau thường quy bằng paracetamol $10 \mathrm{mg} / \mathrm{kg}$ ngay khi kết thúc phẫu thuật.

\subsection{Các tiêu chí đánh giá}

- Đặc điểm chung của nhóm bệnh nhân nghiên cứu

- Tiêu chí mục tiêu 1: Điểm FLACC tại một số thời điểm sau mổ, thời gian giảm đau sau mổ, số lần dùng thêm giảm đau trong $24 \mathrm{~h}$ sau mổ, thời gian phục hồi vận động chân đạt mức Mo sau mổ.

- Tiểu chí mục tiêu 2: tuần hoàn, hô hấp và các tác dụng khồng mong muốn như nôn, bí tiểu, run, sốt, đau vết chọc kim, ngộ độc thuốc tê.

Khi trẻ ra hồi tỉnh: đánh giá 5 phút/lần trong 20 phút đầu, 10 phút/lần trong 1,5 giờ đầu sau mổ, tiếp theo 30 phút/lần trong 5 giờ tại phòng hồi tỉnh.

Khi bệnh nhi về khoa: Trẻ được theo dõi 6 giờ/lần đến 24 giờ sau bởi nhân y tế và người nhà bệnh nhi và khi trẻ đau lại. 
Khi điểm FLACC $\geq 4$ dùng thêm paracetamol TM $15 \mathrm{mg} / \mathrm{kg}$, sau 15 phút đánh giá lại điểm đau, sau khi loại trừ các nguyên nhân khác gây đau cho trẻ, nếu FLACC $\geq 4$ dùng morphin $20 \mathrm{mcg} / \mathrm{kg}$, chú ý nhịp thở của trẻ, lặp lại sau 15 phút liều morphin như trên đến khi FLACC $<4$.

\section{KẾT QUẢ NGHIÊN CỨU}

\section{1. Đặc điểm chung của đối tượng nghiên cứu}

Bảng 2.1 Đặc điểm chung

\begin{tabular}{|c|c|c|c|c|}
\hline \multicolumn{2}{|c|}{ Chỉ tiêu nghiên cứu } & Nhóm I $(n=30)$ & Nhóm II $(n=30)$ & $\mathrm{p}$ \\
\hline Tuổi & $X \pm \mathrm{SD}$ & $39,04 \pm 23,86$ & $33,8 \pm 17,1$ & \multirow{6}{*}{$>0,05$} \\
\hline (Tháng) & Min - Max & $11,6-95,7$ & $13,7-84,7$ & \\
\hline \multirow{2}{*}{$\begin{array}{l}\text { Cân nặng } \\
(\mathrm{Kg})\end{array}$} & $X \pm S D$ & $13,6 \pm 3,83$ & $13,5 \pm 3,2$ & \\
\hline & Min - Max & $8,5-26$ & $9,5-24$ & \\
\hline \multicolumn{2}{|c|}{ Giới (nam/nữ) } & $26 / 4$ & $25 / 5$ & \\
\hline \multicolumn{2}{|c|}{ Thời gian Phẩu thuật } & $18,4 \pm 2,2$ & $23,1 \pm 4,4$ & \\
\hline
\end{tabular}

Nhận xét: Cân nặng, giới tính, tháng tuối, thời gian phấu thuật trung bình của 2 nhóm khác biệt không có ý nghĩa thống kê p > 0,05.

2.2. Đánh giá hiệu quả giảm đau sau mổ. Theo thang điểm Gunter, $90 \%$ đối với nhóm I và $86,7 \%$ đối với nhóm II đạt mức tốt, còn lại là mức trung bình, không có bệnh nhân không đạt.

Thời gian giảm đau sau mổ

Bảng 2.2 Thời gian bắt đâu đau lại sau mổ (phút)

\begin{tabular}{|c|c|c|c|}
\hline $\begin{array}{l}\text { Thời glan Nhóm } \\
\text { (phút) }\end{array}$ & $\begin{array}{c}\text { Nhóm I } \\
(\mathbf{n = 3 0 )}\end{array}$ & $\begin{array}{c}\text { Nhóm II } \\
(\mathbf{n = 3 0 )}\end{array}$ & $\mathbf{p}$ \\
\hline $\begin{array}{c}\bar{X} \text { + SD } \\
\text { (Min - Max) }\end{array}$ & $\begin{array}{c}344 \pm 80.1 \\
(174-455)\end{array}$ & $\begin{array}{c}312 \pm 66.9 \\
(192-480)\end{array}$ & $>0.05$ \\
\hline
\end{tabular}

Nhân xét: Thời gian giảm đau trung bình sau mổ của nhóm I và nhóm II khác nhau không có ý nghĩa thống kê với $p>0,05$.

Số lân dùng thêm giảm đau sau mổ

2.3. Tác dụng không mong muốn và tai biến

\section{Bảng 2.4 Bảng tác dung không mong muốn và tai biến}

\begin{tabular}{|c|c|c|c|c|c|}
\hline \multirow{2}{*}{ Triệu chứng Nhóm } & \multicolumn{2}{|c|}{ Nhóm I $(n=30)$} & \multicolumn{2}{|c|}{ Nhóm II $(n=30)$} & \multirow[b]{2}{*}{ p } \\
\hline & Số bn & $\%$ & Số bn & $\%$ & \\
\hline Buồn nôn và nôn & 1 & 3.3 & 0 & 0 & \multirow{4}{*}{$>0,05$} \\
\hline Ngứa & 2 & 6.7 & 2 & 6.7 & \\
\hline Run & 1 & 3.3 & 0 & 0 & \\
\hline Bí tiếu & 2 & 6.7 & 0 & 0 & \\
\hline
\end{tabular}

Nhận xét: Tỷ lệ buồn nôn, nôn, ngứa, run, bí tiểu của nhóm I và nhóm II khác biệt không có ý nghĩa thống kê với $\mathrm{p}>0,05$.

Các thay đổi về $\mathrm{M}, \mathrm{HA}, \mathrm{SpO}_{2}$ tại các thời điểm sau mổ trong giới hạn bình thường và không có sự khác biệt giữa 2 nhóm.

\section{BÀN LUÂN}

*Đặc điểm chung: tuổi, giới, cân nặng và thời gian phẫu thuật không có sự khác biệt giữa 2 nhóm. Các bệnh nhi có biểu bệnh từ nhỏ, được khám và giải thích phẫu thuật sau 1 tuổi.

*Chất lượng tê theo Gunter: đạt $90 \%$ cho kết quả tốt ở nhóm I, 86,7\% ở nhóm II và không có chất lượng kém hay thất bại ca nào. Ngoài

\section{trong 24 h dâu \\ Bảng 2.3 Số lân dùng thêm giảm đau sau mố

\begin{tabular}{|c|c|c|c|}
\hline $\begin{array}{l}\text { Nhóm Số } \\
\text { lần }\end{array}$ & $\begin{array}{l}\text { Nhóm I } \\
(n=30)\end{array}$ & $\begin{array}{c}\text { Nhóm II } \\
(n=30)\end{array}$ & $\mathbf{p}$ \\
\hline $\begin{array}{c}\bar{X} \pm \text { SD } \\
(\text { Min-Max) }\end{array}$ & $\begin{array}{c}1,1 \pm 0,48 \\
0-2\end{array}$ & $\begin{array}{c}1,07 \pm 0,37 \\
0-2\end{array}$ & $\stackrel{>}{0.05}$ \\
\hline
\end{tabular}

Nhận xét: Số lần dùng thêm giảm đau sau mổ trung bình của hai nhóm là tương đương nhau, khác biệt không có ý nghĩa thống kê với p $>0,05$

Thời gian phục hồi vận động chân sau mổ: Ngay sau khi tỉnh, 100\% bệnh nhân nhóm II vân động được ở mức M0. 30 phút sau khi tỉnh 2 bn ở nhóm I (6.7\%) chưa hồi phục vận động hoàn toàn 
giảm đau lần đầu tiên (FLACC $\geq 4$ ). Theo Bảng 2.2 thời gian giảm đau sau mổ của nhóm I là $344 \pm 80.1$ phút, của nhóm II là $312 \pm 66,9$ phút. Sự khác biệt về thời gian giảm đau trung bình giữa 2 nhóm không có ý nghĩa thống kê với $p>0,05$.

Breschan $C^{7}$ (2005), so sánh GTKC bằng levobupivacain, ropivacain, bupivacain ở cùng nồng độ $0,2 \%$ trong các phẫu thuật vùng dưới rốn trẻ em, thời gian giảm đau sau mổ của levobupivacain $0,2 \%$ là $5,75 \pm 0,65$ giờ, của ropivacain $0,2 \%$ là $5,7 \pm 0,8$ giớ, bupivacain $0,2 \%$ là $5,35 \pm 1,3$ giờ. Tương đương với kết quả nghiên cứu của chúng tôi. Ashraf Abualhassan Abdellatif ${ }^{4}$ (2012), so sánh gây tê khoang cùng bằng bupivacaine $0,25 \%$ liều 0,7 $\mathrm{ml} / \mathrm{kg}$ với gây tê thần kinh chậu bẹn chậu hạ vị bằng bupivacaine $0,25 \%$ liều $0,1 \mathrm{ml} / \mathrm{kg}$ cho phẫu thuật thoát vị bẹn một bên ở trẻ từ $1-6$ tuổi thấy thời gian giảm đau trung bình của từng nhóm lần lượt là $219.6 \pm 48.4$ phút và $253 \pm$ 102.6 phút $(p>0,05)$. Thời gian giảm đau sau mổ ngắn hơn so với nghiên cứu của chúng tôi do tác giả sử dụng thể tích thấp hơn. Số lần thêm giảm đau của cả 2 nhóm đều thấp và tương đương nhau, không có bệnh nhân nào cần sử dụng đến Morphin. Vì đường mổ thoát vị ben là đường mổ nhỏ và mức độ đau không nhiều, phần lớn bệnh nhân được xuất viện vào ngày thứ 2 sau mổ.

*Thời gian phục hồi vận động: đây là tiêu chí rất quan trọng vi ở độ tuổi từ 1- 6 tuổi, trẻ thường hiếu động nên nếu thời gian phụ hồi chậm trẻ có nguy cơ té ngã. Nhóm gây tê chậu bẹn chậu hạ vị có thời gian phục hồi vận động hoàn toàn ngay từ khi tỉnh vì đây là gây tê ngoại vi. Nhóm gây tê khoang cùng 30 phút sau mổ vẫn còn 2 bệnh nhân chưa hồi phục hoàn toàn. Vì vậy, việc theo dõi sát trẻ là rất cần thiết ở nhóm bệnh nhân được vô cảm bằng phương pháp gây tê khoang cùng.

*Tác dụng không mong muốn: Sau mổ các tác dụng không mong muốn được chúng tôi theo dõi trong $24 \mathrm{~h}$ đầu. Tỷ lệ nôn buồn nôn của 2 nhóm đều thấp và không có sự khác biệt do các bệnh nhân đã được dùng thuốc chống nôn dự phòng đầy đủ. Tướng tự như vậy tỷ lệ ngứa, rét run cũng cho kết quả không khác biệt giữa 2 nhóm. Bí tiểu được xác định khi bệnh nhân có cầu bàng quang và không tự đi tiểu được nếu không có can thiệp như lý liệu pháp hay đặt ống thông bàng quang. Trong nghiên cứu của chúng tôi, ở nhóm I có 2 bệnh nhân $(6,7 \%)$ bí tiểu vì đây là nhóm gây tê trung ương, nhóm II không có bệnh nhân nào, sự khác biệt không có ý nghĩa thống kê với $p>0.05$ có thể do cỡ mâu của chúng tôi nhỏ. Tuy nhiên số bệnh nhân bí tiểu ở nhóm I chỉ dùng lí liệu pháp không bệnh nhân nào phải đă̆t sonde bàng quang. Nghiên cứu của Bùi Thị Thanh ${ }^{8}$ thấy tỷ lệ bệnh nhân bí tiểu là $4,3 \%$ sau gây tê khoang cùng bằng levobupivacaine $0,2 \%$, phù hợp với kết quả nghiên cứu của chúng tôi. Các tác dụng không mong muốn khác như ngộ độc thuốc tê, sốt, chọc thủng màng cứng, tụ máu khoang cùng, liệt chi dưới không hồi phục, chọc vào mạch máu không gặp trong nghiên cứu của chúng tôi.

\section{KẾT LUÂNN}

Chất lượng gây tê và giảm đau sau mổ của 2 nhóm đều đạt ở mức tốt. Thời gian phục hồi vận động của nhóm gây tê chậu bẹn chậu hạ vị nhanh hơn. Các tác dụng phụ của 2 nhóm đều ở mức thấp và không nguy hiểm, nhóm gây tê khoang cùng có tỷ lệ bí tiểu nhiều hơn nhưng không cần can thiệp.

\section{TÀI LIỆU THAM KHẢO}

1. Martinoli $C$. Imaging of the peripheral nerves. Seminars in musculoskeletal radiology. 2010;14(5):461-462.

2. Willschke $H$, Marhofer $P$, Bösenberg A, et al Ultrasonography for ilioinguinal/iliohypogastric nerve blocks in children. 2005;95(2):226-230.

3. Willschke $H$, Marhofer $P$, Bösenberg $A$, et al. Ultrasonography for ilioinguinal/iliohypogastric nerve blocks in childrent. BJA: British Journal of Anaesthesia. 2005;95(2):226-230.

4. Abdellatif AA. Ultrasound-guided ilioinguinal/ iliohypogastric nerve blocks versus caudal block for postoperative analgesia in children undergoing unilateral groin surgery. Saudi J Anaesth. 2012;6(4):367-372.

5. Yang $\mathbf{L}, \mathbf{X u} \mathbf{Y}$, Wang Z, Zhang $\mathbf{W}$. Application of Ultrasound-Guided Ilioinguinal/Iliohypogastric Nerve Block in Pediatric Same-Day Surgery. Indian J Surg. 2015;77(6):512-516.

6. Takasaki M, Dohi S, Kawabata Y, Takahashi T. Dosage of lidocaine for caudal anesthesia in infants and children. Anesthesiology. 1977; 47(6):527-529.

7. Breschan $C_{\text {, Jost }}$, Krumpholz R, et al. A prospective study comparing the analgesic efficacy of levobupivacaine, ropivacaine and bupivacaine in pediatric patients undergoing caudal blockade. Paediatr Anaesth. 2005;15(4):301-306.

8. Bùi Thi Thanh. Nghiên cứu gây tê khoang cùng bằng hồn hợp levobupivacain và sufentanil trong các phẫu thuật vùng dưới rốn ở trẻ em. Học viện quân y. 2015. 